\title{
Elevation in D-dimer concentrations is positively correlated with gestation in normal uncomplicated pregnancy
}

This article was published in the following Dove Press journal:

International Journal of Women's Health

30 August 2012

Number of times this article has been viewed

\author{
Zaccheaus A Jeremiah' \\ Teddy C Adias ${ }^{2}$ \\ Margaret Opiah ${ }^{3}$ \\ Siyeoforiye P George ${ }^{4}$ \\ Osaro Mgbere ${ }^{5}$ \\ Ekere J Essien ${ }^{6}$ \\ 'Department of Medical Laboratory \\ Sciences, Niger Delta University, \\ Wilberforce Island, Nigeria; ${ }^{2}$ Bayelsa \\ State College of Health Technology, \\ Ogbia-Town, Nigeria; ${ }^{3}$ Department \\ of Maternal and Child Health, \\ Faculty of Nursing, Niger Delta \\ University, Wilberforce Island, Nigeria; \\ ${ }^{4}$ Postgraduate Hematology Unit, \\ Rivers State University of Science and \\ Technology, Port Harcourt, Nigeria; \\ ${ }^{5}$ Houston Department of Health and \\ Human Services, Houston, TX, USA; \\ ${ }^{6}$ Institute of Community Health, \\ University of Houston, Houston, \\ TX, USA
}

Correspondence: Teddy C Adias Bayelsa State College of Health

Technology, Otuogidi,

Ogbia-Town, PMB I3I,

Yenegoa, Nigeria

Tel +234803 313 030l

Email teddyadias@yahoo.com

Zaccheaus A Jeremiah

Department of Medical Laboratory

Sciences, College of Health Sciences,

Niger Delta University,

Wilberforce Island,

Bayelsa State, Nigeria

Email zacjerry@yahoo.com
Background: D-dimer levels have been reported to increase progressively during pregnancy, but how this affects Nigerian women is not well known.

Objective: This study aims to determine the D-dimer concentration and its relationship to other coagulation parameters among pregnant women in Port Harcourt, Nigeria.

Method: In a cross-sectional observational study conducted in Port Harcourt, Nigeria, 120 pregnant women and 60 nonpregnant controls, drawn from a tertiary health institution in the Niger Delta, Nigeria, were assessed, using the standard procedures, for the following parameters: D-dimer concentration, prothrombin time, activated partial thromboplastin time, platelet count, hemoglobin, and packed cell volume.

Results: The median D-dimer concentration of $153.1 \mathrm{ng} / \mathrm{mL}$ in the pregnant group was found to be significantly elevated when compared with the control value of $118.5 \mathrm{ng} / \mathrm{mL}(t=2.348$, $P=0.021)$. Conversely, there was a marked depression in the platelet count among pregnant women $\left(193.5 \times 10^{9} / \mathrm{L}\right)$ when compared with $229.0 \times 10^{9} / \mathrm{L}$ in the control group $(t=3.424$; $P=0.001)$. There was no statistically significant difference in the values for the prothrombin time and the activated partial thromboplastin time between pregnant and nonpregnant women. D-dimer values correlated positively and significantly with gestation $(\mathrm{r}=0.36 ; P<0.01)$ and negatively with international normalized ratio values $(\mathrm{r}=-0.281 ; P<0.05)$. About $63.3 \%$ of the pregnant women had normal D-dimer values $(0-200 \mathrm{ng} / \mathrm{mL}), 26.7 \%$ of the pregnant women had elevated D-dimer levels $(201-499 \mathrm{ng} / \mathrm{mL})$, while $10.0 \%$ of the pregnant women were found to be at risk of thrombosis (D-dimer $>500 \mathrm{ng} / \mathrm{mL}$ ). A linear relationship was found to exist between D-dimer and gestation $\left(\mathrm{y}=8.355 \mathrm{x}+36.55 ; \mathrm{R}^{2}=0.130 ; P<0.005\right)$.

Conclusion: $10 \%$ of the pregnant women in this population had elevated $\mathrm{D}$-dimer levels over $500 \mathrm{ng} / \mathrm{mL}$, and through comparison with what has been reported in the literature, there is the possibility that this group may be at risk of thrombosis. Further studies, incorporating other diagnostic parameters, may be needed before a more logical conclusion can be drawn, since the D-dimer is not a specific test.

Keywords: D-dimer, prothrombin time, activated partial thromboplastin time, pregnancy, Nigeria

\section{Introduction}

In a normal hemostatic process, the cessation of blood loss following injury involves the formation of a physical plug of aggregated platelets at the site of the injury, which is further stabilized by the protein fibrin that is produced locally, in response to the injury, by the coagulation cascade. ${ }^{1}$ Further activation of the coagulation cascade produces thrombin, an enzyme that cleaves fibrinopeptides A and B from fibrinogen to form fibrin monomers. ${ }^{2}$ Thrombin activates factor XIII, which then 
catalyzes cross-linking between the D-domains of adjacent fibrin monomers, thus stabilizing the fibrin polymer. The activation of the coagulation cascade, which is necessary for the formation of the fibrin clot, is accompanied by activation of the fibrinolytic system, which involves the breakdown of the fibrin (fibrinolysis), with a resultant fibrin clot dissolution, to form the D-dimers. ${ }^{3}$ D-dimers are therefore protein products of cross-linked fibrin degradation, which are present in the blood of most healthy individuals only in negligible amounts, in the order of $100-200 \mathrm{ng} / \mathrm{mL} .^{2}$ Increased blood D-dimer concentration, which is objective evidence of ongoing fibrinolysis, is, by extension, evidence of intravascular coagulation and thrombotic disease (venous thromboembolism). The absence of D-dimers in blood plasma excludes intravascular clot formation (thrombosis), and, conversely, raised plasma D-dimers suggests an ongoing thrombotic/fibrinolytic process. ${ }^{2}$

In the late $1980 \mathrm{~s}$, soon after the commercial development of the first D-dimer assay systems, it was presumed that the test would prove useful in the diagnosis of thrombotic disease. However, it soon became clear that a range of physiological and pathological conditions, including pregnancy, was associated with the same positive D-dimer results found in those with overt thrombotic disease.,4-6 Since the D-dimer has been reported to have low specificity, but high sensitivity, for thrombotic disease, $500 \mathrm{ng} / \mathrm{mL}$ was widely held as the consensus cut-off point for diagnosing or ruling out thrombosis in smokers and pregnant women. ${ }^{2}$ There is a dearth of information on the D-dimer levels of pregnant Nigerian women. This study was designed to: (1) determine the D-dimer levels of pregnant and nonpregnant women and compare their values for statistical significance; (2) identify the proportion of pregnant women that are at risk of developing thrombosis; and (3) identify the risk factors associated with the development of thrombosis.

\section{Methods}

\section{Study population}

The study population consisted of 180 women randomly selected from those attending the antenatal clinic of the University of Port Harcourt Teaching Hospital, Port Harcourt, Nigeria. One hundred and twenty of the women were pregnant, while the remaining 60 women were not pregnant and were selected from the female staff of the hospital to serve as controls (Table 1). Their ages ranged from 16-41 years (mean $28.4 \pm 4.2$ ) for the pregnant women and 13-65 years (mean $30.2 \pm 9.5$ ) for the controls. They were all apparently healthy subjects with no clinical signs of complications or the presence of comorbidities. The study received ethical approval from the committee for the protection of human subjects at both the Rivers State University of Science and Technology and the University of Port Harcourt Teaching Hospital in Port Harcourt, Nigeria. Thereafter, oral informed consent was received from the volunteers before blood samples were collected from them. All the nonpregnant women were confirmed to be negative using one-step pregnancy strips (SD Bioline hcG strip; Standard Diagnostics, Inc, Kyonggi-do, Korea). Women who had family histories of thromboembolic diseases, HIV, or pre-eclampsia were excluded from the study.

\section{Sample collection}

A qualified phlebotomist drew $5 \mathrm{~mL}$ of whole blood, using a disposable syringe, through a venipuncture procedure. About $2.5 \mathrm{~mL}$ of the blood was transferred into a tube containing sodium citrate anticoagulant solution. This was mixed on the roller mixer machine and centrifuged for 15 minutes at $1500 \mathrm{~g}$. The plasma was collected at the end of centrifugation and used for the D-dimer assay, prothrombin time (PT), and activated partial thromboplastin time (aPTT). The remaining $2.5 \mathrm{~mL}$ was transferred into a tube containing dipotassium ethylene diamine tetraacetic acid and used for the determination of packed cell volume (PCV), platelets, and hemoglobin. All samples for the D-dimer assay were achieved at $-20^{\circ} \mathrm{C}$ until they were analyzed using the enzyme linked immunosorbent assay (ELISA) procedures.

\section{Quantitative D-dimer concentration}

The D-dimer concentration was estimated using the ELISA technique with the Technozym D-dimer ELISA kit. (Reference number 259906, Lot number RH92A00; Technoiclone $\mathrm{GmDH}$, Vienna, Austria). Then, $100 \mu \mathrm{L}$ of the controls (high and low) and the diluted samples were pipetted into the test wells and covered with film. This was followed by incubation at $37^{\circ} \mathrm{C}$ for 60 minutes, after which the test wells were washed with $200 \mu \mathrm{L}$ of buffer $\mathrm{pH}$ 7.3. Anti-dimer (conjugate working solution) was then pipetted into the wells, which were covered with film and incubated for another 60 minutes. This second incubation period was again followed by three washes using $200 \mu \mathrm{L}$ of washing buffer concentrate. This was followed by the addition of $100 \mu \mathrm{L}$ of chromogen tetraethylbenzidine into the test wells, which were covered with film and incubated for 10 minutes. After a substrate reaction for 10 minutes, a stopping solution of $100 \mu \mathrm{L}$ was added to the test wells, which were shaken 
for 10 minutes; a golden yellow color was seen to develop. The absorbance was read in an ELISA reader (Stat Fax ${ }^{\circledR}$; Awareness Technology, Inc, Palm City, FL), using a wavelength of $450 \mathrm{~mm}$, within 10 minutes. The D-dimer concentration of the samples and the high and low control values were obtained by extrapolation from the standard calibration curve obtained by plotting the absorbance against the concentration of the reference standard.

\section{Prothrombin time}

A one-stage procedure was employed in the PT determination. About $0.2 \mathrm{~mL}$ of thromboplastin-calcium reagent (Diagnostic Reagents Ltd, Thame, UK) was placed in the clotting tube in a water bath at $37^{\circ} \mathrm{C}$ and left for 2 or 3 minutes until it reached $37^{\circ} \mathrm{C}$. Approximately $0.1 \mathrm{~mL}$ of plasma was then added and a stop watch was started, after which the tube was gently tilted for a 2- or 3-second interval, and the formation time for the clot was recorded.

\section{Activated partial thromboplastin time}

About $0.2 \mathrm{~mL}$ of Kaolin platelet substitute (Diagnostic Reagents Ltd) was placed in a clotting tube and $0.1 \mathrm{~mL}$ of plasma was added; the tube was gently tilted at intervals for exactly 2 minutes. Approximately $0.1 \mathrm{~mL}$ of $0.025 \mathrm{~mL}$ calcium chloride was then added and a stopwatch was started. The tube was tilted for 3 - to 5-second interval and the clotting time was recorded. The test was carried out in duplicate for both the control and subject samples.

\section{Platelet counts}

The platelet count was carried out using procedures approved by the International Council for Standardization in Haematology (ICSH). ${ }^{7}$ Well-mixed whole blood was diluted with $1 \%$ ammonium oxalate at a ratio of 1 to $19(50 \mu \mathrm{L}$ of blood to $950 \mu \mathrm{L}$ of the anticoagulant). The hemocytometer was then filled with an aliquot of this mixture and allowed to settle for 1 minute prior to performing the count. Platelets were counted in one small central square and the number was calculated using the first principle: cells counted $\times$ dilution factor $\times$ chamber depth/area of the chamber counted. Results were expressed as the number of platelets $\times 10^{9} / \mathrm{L}$ (SI units).

\section{Packed cell volume}

PCV estimation was conducted using the microhematocrit centrifuge (Andreas Hettich $\mathrm{GmbH}$ and $\mathrm{Co}, \mathrm{KG}$, Tuttlingen, Germany) and the results obtained were expressed as percentages.

\section{Statistical analysis}

Data obtained from the study were subjected to descriptive statistics (mean, standard deviation, median, etc). The normality of the distribution was tested using the KolmogorovSmirnov test. The differences between the subject and control groups for the measured parameters were determined using the $t$-test, while correlation and regression analyses were used to determine the relationship between the variables. Data management and statistical analyses were conducted using SPSS software version 17.0 (SPSS Inc, Chicago, IL). All statistical tests used the probability value of $P<0.05$ as the significance level.

\section{Results}

Table 2 shows the mean and median values of the parameters assessed. The mean age of the subjects (28.4 years) did not differ significantly from that of the control group (30.2 years) $(t=1.256, P=0.212)$. The median $\mathrm{D}$-dimer value of $153.1 \mathrm{ng} / \mathrm{Ml}^{-1}$ in the pregnant group was found to be significantly elevated when compared with the control median value of $118.5 \mathrm{ng} / \mathrm{mL}^{-1}(t=2.348, P=0.021)$. Results for this study indicate that the range of the D-dimer concentration observed was $0-562.5 \mathrm{ng} / \mathrm{mL}$. The low control value was $125 \mathrm{ng} / \mathrm{mL}$, while the high control value was $562.5 \mathrm{ng} / \mathrm{mL}$. Conversely, there was a marked depression in the platelet count among pregnant subjects $(193.5 \times 109 / \mathrm{L})$ when compared with the count $(229 \times 109 / \mathrm{L})$ obtained for the control group $(t=3.424, P=0.001)$. There was no statistically significant difference in the prothrombin time between the subjects and controls $(P>0.01)$, but the ratio showed a statistically significant difference between the pregnant women and the control group $(t=2.588$, $P=0.01)$. No significant difference was observed in the aPTT values between the pregnant women and the control group $(t=1.654, P=0.102)$.

Table 3 shows the Pearson correlation values of the parameters assessed. The D-dimer was correlated positively with gestation $(\mathrm{r}=0.361, P<0.01)$. No significant correlation existed between the D-dimer and the other parameters (Figures 1-3).

Table I Characteristics of study population

\begin{tabular}{lll}
\hline Subjects & Number & Percentage \\
\hline Pregnant women & 120 & 66.7 \\
Ist trimester & 20 & $\mathrm{II} . \mathrm{I}$ \\
2nd trimester & 80 & 44.4 \\
3rd trimester & 20 & $\mathrm{II} . \mathrm{I}$ \\
Controls (nonpregnant women) & 60 & 33.3 \\
\hline
\end{tabular}




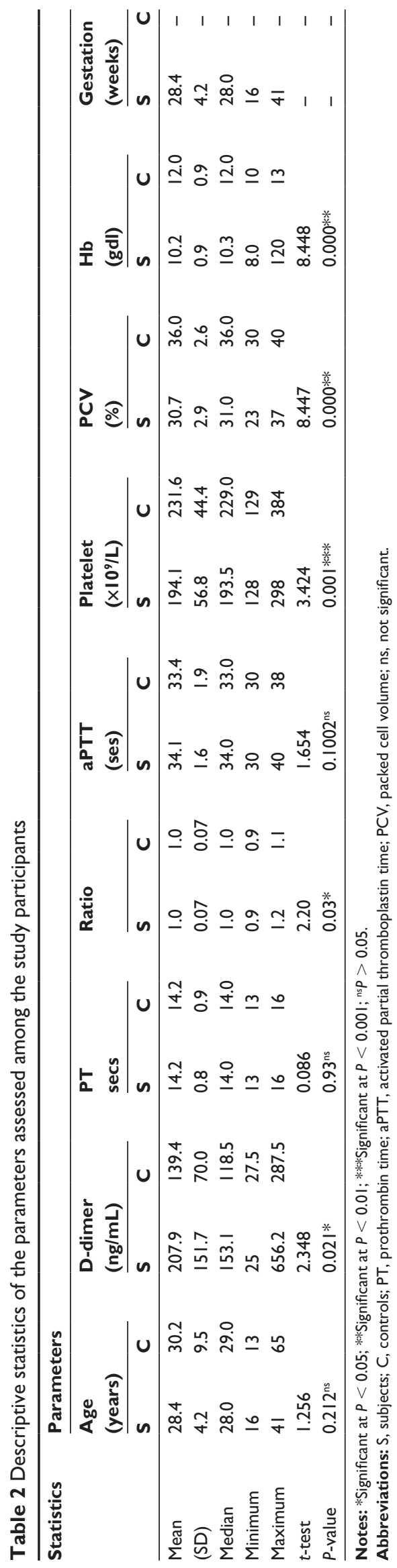

Using three different cut-off values, both the pregnant women and the control subjects were classified into three groups, as follows: $63.3 \%$ of the pregnant women had normal D-dimer values $\left(0-200 \mathrm{ng} / \mathrm{mL}^{-1}\right)$, compared with $73.3 \%$ in the control group, while $26.7 \%$ of the pregnant women had elevated D-dimer (201-499 ng/mL $\left.\mathrm{mL}^{-1}\right) .10 .0 \%$ of the pregnant women were found to be at risk of thrombotic disease, with a D-dimer value of $500 \mathrm{ng} / \mathrm{mL}$ or higher. None of those in the control group were at risk of thrombosis (ie, none had a D-dimer value of $500 \mathrm{ng} / \mathrm{mL}$ ). Pearson chi-square values did not show any association between the subject and control groups in regard to the D-dimer values $\left(\chi^{2}=3.300\right.$, $P=0.192)$.

Regression analysis revealed that a linear relationship exists between $\mathrm{D}$-dimer values and the gestation periods in pregnancy $\left(\mathrm{y}=8.355 \mathrm{x}+36.55 ; \mathrm{R}^{2}=0.130, P=0.005\right)$. No relationship was found to exist between age and D-dimer values $\left(\mathrm{y}=2.506 \mathrm{x}+112.2, \mathrm{R}^{2}=0.014, P=0.088\right)$.

\section{Discussion}

While most of the studies in the literature used qualitative methods to assess D-dimer levels, our study describes a quantitative ELISA measurement of D-dimer concentrations in pregnant women. This study is therefore unique, based on the fact that there are currently no known reports from Nigeria with comparable information. The main findings of this study are: (1) a greater proportion (26.7\%) of the study population recorded elevated levels of D-dimer; (2) a high percentage of pregnant women $(10.0 \%)$ may be at risk of thrombosis; (3) a significant reduction in the platelet counts was noted among the pregnant women; and (4) a positive and significant relationship exists between gestation/trimesters and D-dimer levels.

Pregnancy has been classified as one of the risk factors for thrombosis, with the risk increasing by a factor of 4.2 during pregnancy and rising to 14.4 in the postpartum period, and this high risk of thrombosis has been reported to last up to six weeks after delivery. ${ }^{4,8}$ Consequently, with $10 \%$ of our study population at risk of thrombosis (with a cut-off value of $>500 \mathrm{ng} / \mathrm{mL}$ D-dimer concentration), our study found corroboration with several other studies carried out in other parts of the world, which indicates that pregnancy predisposes women to a risk of thrombosis. ${ }^{3,5,8,9}$ The interpretation of the D-dimer level depends on which test is used to perform the assay, as well as the cut-off values used. ${ }^{16}$ Current recommendations suggest that a D-dimer test should be used in combination with other tests, such as compression ultrasonography and chest radiographs..$^{10,11}$ 
Table 3 Pearson correlation of the parameters estimated in the pregnant women

\begin{tabular}{|c|c|c|c|c|c|c|c|c|c|}
\hline & Age & Gestation & D-dimer & PT & Ratio & Platelet count & PCV & $\mathrm{Hb}$ & aPTT \\
\hline Age & 1.000 & & & & & & & & \\
\hline Gestation & 0.055 & 1.000 & & & & & & & \\
\hline D-dimer & 0.222 & $0.36 I^{* *}$ & 1.000 & & & & & & \\
\hline PT & -0.061 & 0.023 & -0.190 & 1.000 & & & & & \\
\hline Ratio & -0.147 & 0.008 & $-0.312 *$ & $0.821^{* *}$ & 1.000 & & & & \\
\hline Platelet count & 0.053 & -0.132 & -0.109 & 0.132 & 0.079 & 1.000 & & & \\
\hline PCV & -0.123 & $-0.262^{*}$ & -0.102 & 0.185 & $0.319 *$ & -0.088 & 1.000 & & \\
\hline $\mathrm{Hb}$ & -0.123 & $-0.256^{*}$ & -0.097 & 0.185 & $0.298 *$ & $0.999 * *$ & 1.000 & 1.000 & \\
\hline aPTT & 0.178 & -0.009 & -0.019 & 0.191 & 0.074 & -0.048 & -0.088 & -0.080 & 1.00 \\
\hline
\end{tabular}

Notes: *Correlation is significant at the 0.05 level $(P<0.05)$; **Correlation is significant at the 0.01 level $(P<0.01)$.

Abbreviations: PT, prothrombin time; aPTT, activated partial thromboplastin time; PCV, packed cell volume.

Another significant observation in this study is the progressive rise, up to $600 \mathrm{ng} / \mathrm{mL}$, in the $\mathrm{D}$-dimer concentration during the second and third trimesters of pregnancy. This observation affirms earlier reports by several researchers. ${ }^{6,12-15}$ Historically, the D-dimer test was used to determine increased fibrinolytic activity in various physiological and therapeutic states; thus, an elevated D-dimer level in a patient's blood indicates two physiological processes: the presence of an intravascular thrombus and the normal degradation (fibrinolysis) of the thrombus. ${ }^{16}$ The increase in the D-dimer is a result of the interplay between several fibrinolytic factors. Physiologically, the tissue plasminogen activator converts plasminogen into plasmin, which cleaves fibrin and fibrinogen, yielding fibrin degradation products. A plasmin inhibitor ( $\alpha 2$-antiplasmin) and plasmin activator inhibitor type 1 and type 2 (PAI-1 and PAI-2) prevent excess fibrin degradation by plasmin. Endothelial-derived
PAI-1 increases during the later stages of pregnancy, whereas placenta-derived PAI-2, detectable in the plasma during the first trimester, increases substantially throughout pregnancy. ${ }^{17}$ Taken together, these changes suggest that during normal pregnancy the fibrinolytic system is impaired. However, the plasminogen levels also increase during pregnancy, and the $\alpha 2$-antiplasmin correspondingly decreases during the period, while the D-dimers and fibrin degradation products tend to increase. These physiological processes may explain why the D-dimer levels in this study increased with gestations and trimesters. The presence of D-dimer as a marker of fibrinolysis is indicative of a substantial increase in fibrinolytic system activation, possibly to counter-balance the increases in coagulation factors observed in normal pregnancy, thus leading to the relatively low incidence of venous thromboembolism in normal pregnancy. ${ }^{17}$ Contrastingly, in this study, no significant changes were observed in the prothrombin time and activated

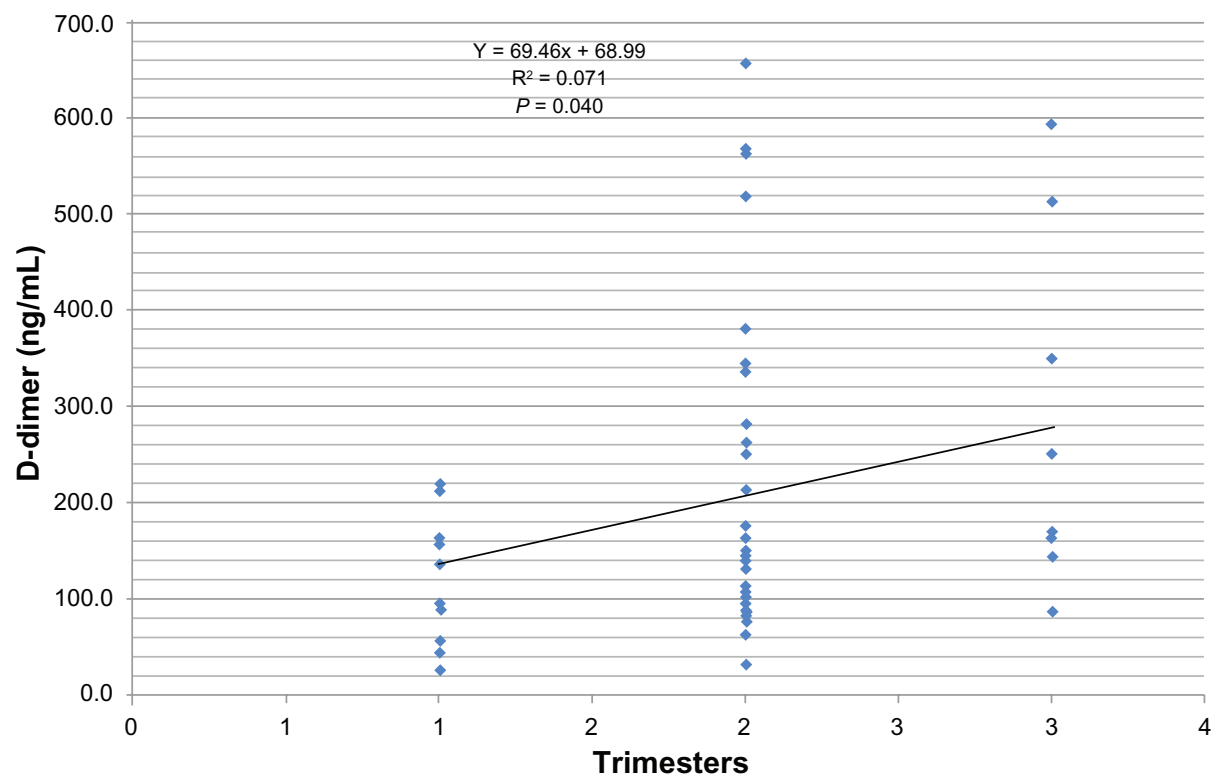

Figure I Relationship between trimesters and D-dimer values of the pregnant women. 


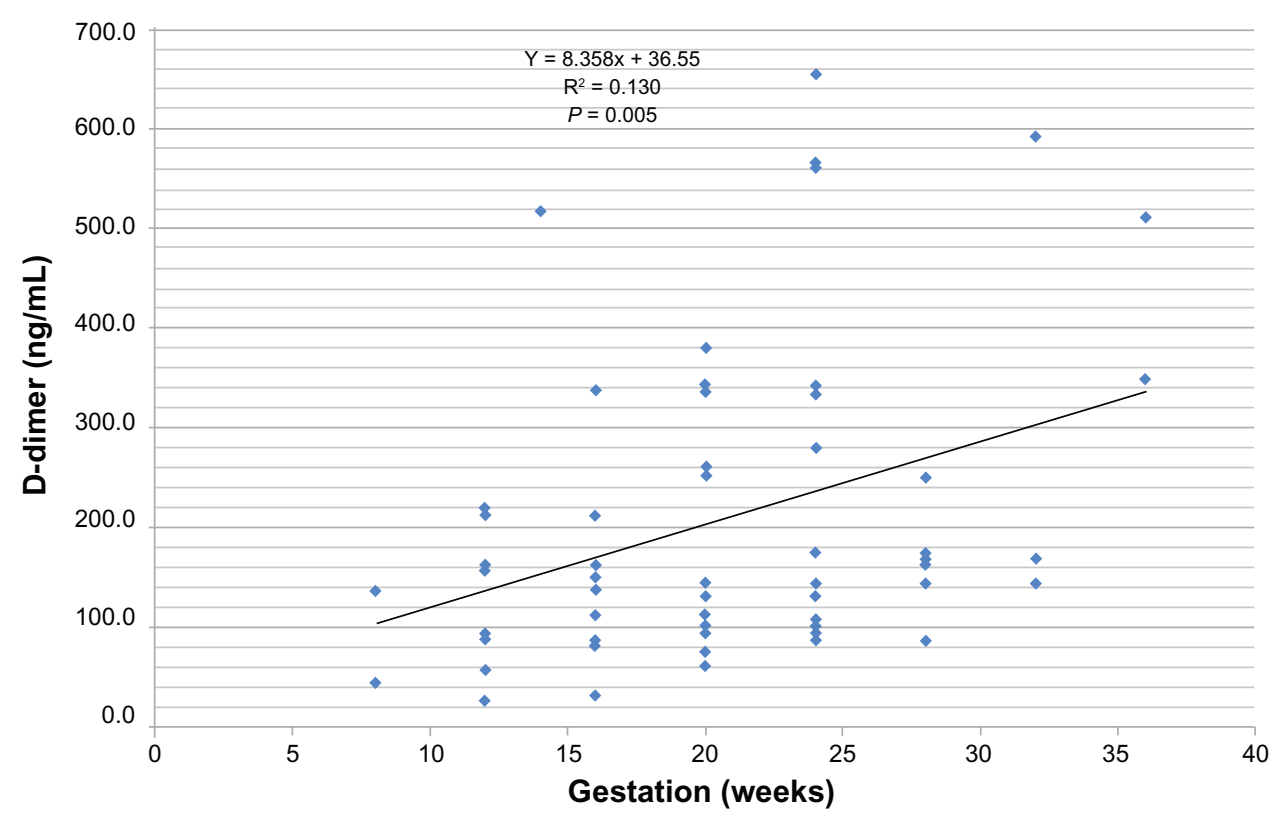

Figure 2 Relationship between gestation and D-dimer values of the pregnant women.

partial thromboplastin time, which measure both the intrinsic and the extrinsic coagulation pathways. It is deducible that the absence of a significant increase in the coagulation factors in this pregnant population may contribute to the higher levels of D-dimer ( $>500 \mathrm{ng} / \mathrm{mL})$, thereby predisposing the pregnant women to a risk of venous thrombosis. For proper assessment of the risk of thrombosis, it would be necessary to measure the activities of the tissue plasminogen activator, PAI-1, PAI-2, $\alpha 2$-antiplasmin, and plasminogen levels. The $10 \%$ of pregnant women with D-dimer concentrations above the $>500 \mathrm{ng} / \mathrm{mL}$ cut-off level could be described as being at risk of venous thrombosis.

Increased D-dimer levels have also been linked to age in a PROLONG study by Shehata et al. ${ }^{18}$ In their study, they reported that patients with an abnormal D-dimer test were much older. Their observation is contrary to what was observed in the current study. In this study, age was not found to exert any influence on the D-dimer levels obtained, nor did regression analysis show any evidence of a relationship. Thus, it is difficult to say that age was a contributory factor

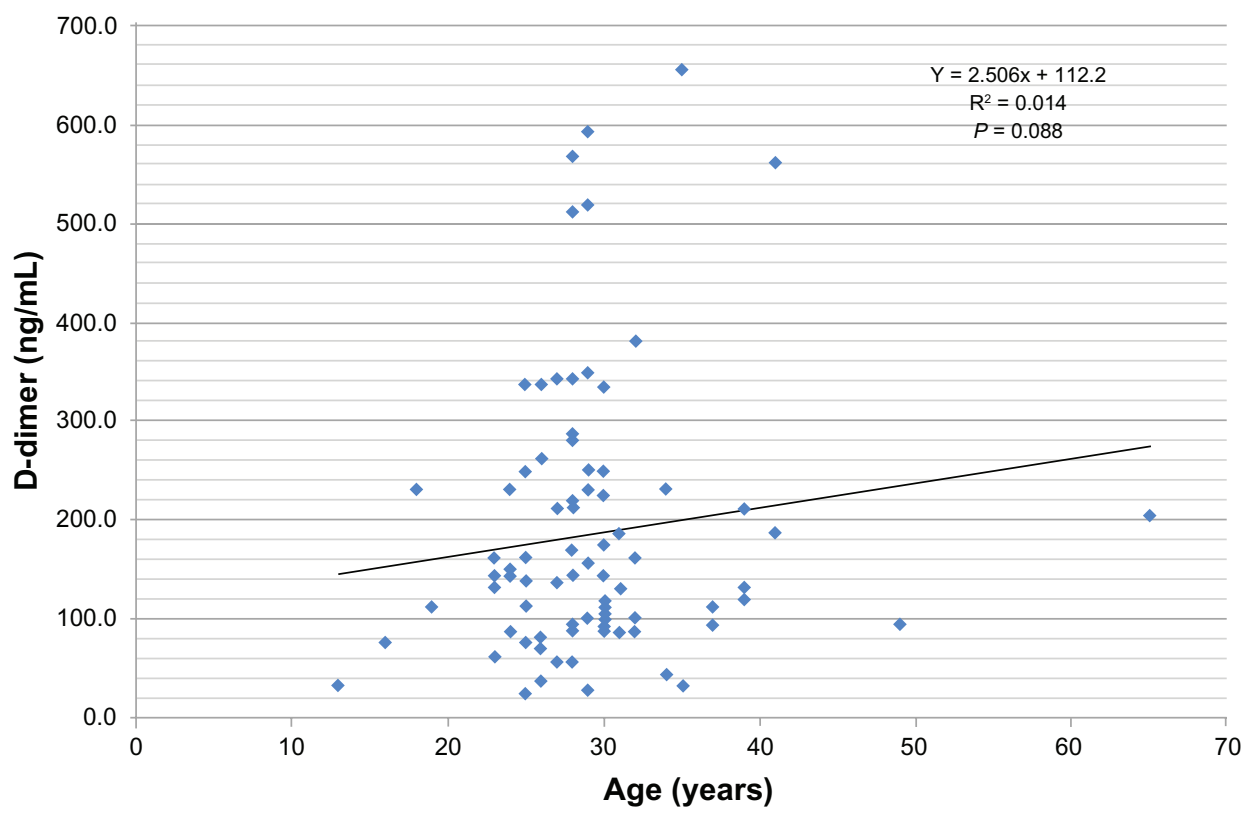

Figure 3 Relationship between age and D-dimer values of the nonpregnant controls. 
to the elevated D-dimer levels. The prothrombin time measures factors VII, X, V, prothrombin, and fibrinogen. Normal time was 10-14 seconds (common in liver disease + Warfarin therapy). The activated partial thromboplastin time measures factors VIII, IX, XI, and XII, in addition to factors X, V, prothrombin, and fibrinogen (hemophilia B ["Christmas factor"] + intravascular coagulation + heparin therapy). The platelet count was also depressed during pregnancy, in accordance with the pattern previously reported in Nigeria, ${ }^{16}$ but no significant correlation was found to exist between D-dimer levels and platelet count. Although thrombocytopenia was not established in this study, there was evidence to show that pregnancy caused a significant reduction in the platelet count $(194.1 \pm 56.8 \times 109 / 1)$ when compared with the nonpregnant control value of $231.6 \pm 44.4 \times 109 / 1$. Thrombocytopenia is classically defined as a platelet count of less than $150,000 / \mu \mathrm{L} .^{18,19}$ The cause of gestational thrombocytopenia remains unclear, although it might be due to an accelerated platelet consumption and the increased plasma volume associated with pregnancy.

\section{Conclusion}

Ten percent of the pregnant women in this population had elevated D-dimer levels above $500 \mathrm{ng} / \mathrm{mL}$; when compared with what has been reported in the literature, there is a possibility that this group may be at risk of thrombosis. Further studies, incorporating other diagnostic parameters, may be needed before a more logical conclusion can be drawn, since the D-dimer is not a specific test.

\section{Disclosure}

The authors report no conflicts of interest in this work.

\section{References}

1. Hoffbrand AV, Pettit JE, Moss PAH. Essential Hematology, 4th ed. Oxford: Blackwell Science; 2002.

2. Prisco D, Cam G, Falcani M. Hemostatic changes in normal pregnancy Haematol Meet Rep. 2005;1:1-5.
3. Higgins C. D-dimer measurement: a novel use for an established test? The Biomedical Scientist. 2008;52:1049-1051.

4. Kline JA, Williams GW, Hernandez-Nino J. D-dimer concentrations in normal pregnancy: new diagnostic thresholds are needed. Clin Chem. 2005;51:825-829.

5. Boehlen F, Epiney M, Boulvain M, Irion O, de Moerloose P. [Changes in D-dimer levels during pregnancy and the postpartum period: results of two studies]. Rev Med Suisse. 2005;1:296-298. French.

6. Francalanci I, Comeglio P, Allessandrello Liotta A, et al. D-dimer plasma levels during normal pregnancy measured by specific ELISA. Intl J Clin Lab Res. 1997;27:65-67.

7. ICSH. International Committee for Standardization in Haematology handbook. 1986:7.

8. Planner G, Kilgert K. Obstetric bleeding complications. Hamostaseologie. 2006;26(Suppl 1):S56-S63.

9. Marik PE, Plante LA. Venous thromboembolic disease and pregnancy. N Engl J Med. 2008;359:2025-2033.

10. Nijkeuter M, Huisman MV. Diagnosing pulmonary embolism in pregnancy: Is there a role for D-dimer as a stand-alone test? Crit Care Med. 2006;34:2701-2702.

11. Nelson-Piercy C. Thromboprophylaxis during pregnancy, labour and after vaginal delivery. Guidelines 37. London: Royal College of Obstetricians and Gynaecologists; 2004.

12. Nolan T, Smith R, Devoe L. Maternal plasma D-dimer levels in normal and complicated pregnancies. Obstet Gynecol. 1993;81:235-238.

13. Morse M. Establishing a normal range for D-dimer levels through pregnancy to aid in the diagnosis of pulmonary embolism and deep vein thrombosis. J Thromb Haemost. 2004;2:1202-1204.

14. Bellart J, Gilabert R, Fontcuberta J, Carreras E, Miralles RM, Cabero L. Coagulation and fibrinolysis parameters in normal pregnancy and in gestational diabetes. Am J Perinatol. 1998:15:479-486.

15. Buseri FI, Jeremiah ZA, Kalio FG. Influence of pregnancy and gestation period on some coagulation parameters among Nigerian antenatal women. Res J Med Sci. 2008;2:275-281.

16. Gosselin RC, Owings JT, Jacoby RC, Larkin EC. Evaluation of a new automated quantitative d-dimer, Advanced D-dimer, in patients suspected of venous thromboembolism. Blood Coagul Fibrinolysis. 2002;13:323-330

17. Palareti G, Cosmi B, Legnani C, et al. D-dimer testing to determine the duration of anticoagulation therapy. $N$ Engl J Med. 2006;355: $1780-1789$

18. Shehata N, Burrows R, Kelton JG. Gestational thrombocytopenia. Clin Obstet Gynecol. 1999;42:327-334.

19. Levy JA, Murphy LD. Thrombocytopenia in pregnancy. J Am Board Fam Pract. 2002;15:290-297.
International Journal of Women's Health

\section{Publish your work in this journal}

The International Journal of Women's Health is an international, peerreviewed open-access journal publishing original research, reports, reviews and commentaries on all aspects of women's healthcare including gynecology, obstetrics, and breast cancer. Subject areas include: Chronic conditions (migraine headaches, arthritis, osteoporosis);

\section{Dovepress}

Endocrine and autoimmune syndromes; Sexual and reproductive health; Psychological and psychosocial conditions. The manuscript management system is completely online and includes a very quick and fair peer-review system. Visit http://www.dovepress.com/ testimonials.php to read real quotes from published authors. 